\title{
HARLEQUIN FOETUS - CONGENITAL ICHTHYOSIS - A CASE REPORT
}

Shery Angel Rajakumar' ${ }^{1}$, Thirumal R², A. P. Nalini ${ }^{3}$, Anurag Vashista ${ }^{4}$, Rontgen $\mathrm{R}^{5}$

\section{HOW TO CITE THIS ARTICLE:}

Shery Angel Rajakumar, Thirumal R, AP Nalini, Anurag Vashista, Rontgen R. "Harlequin foetus - congenital ichthyosis - a case report". Journal of Evolution of Medical and Dental Sciences 2013; Vol2, Issue 32, August 12; Page: 6084-6088.

ABSTRACT: Congenital ichthyosis, also called harlequin foetus is a lethal autosomal recessive disorder resulting from a keratinizing disorder. Harlequin Ichthyosis is a very rare condition and the exact incidence is not known (1). Here is a case report of Mrs. X G2P1D1 at 27 weeks of gestation whose previous baby had Harlequin Ichthyosis and died two months after birth, now the present pregnancy scan report showing features of Harlequin Ichthyosis. The disorder is fatal with neonates suffering from dehydration, infection (sepsis), restricted breathing due to plating. The disease has been known since $5^{\text {th }}$ April 1750 and was first described in the diary of a cleric from Charleston, South Carolina.

KEYWORDS: Harlequin Ichthyosis, autosomal recessive, dysmorphic facies, skin biopsy.

INTRODUCTION: Ichthyosis is regarded as a disorder of keratinization or cornification and it is due to abnormal differentiation or metabolism. It is a very rare condition. There are many types of Ichthyosis and they are classified based on their appearance and their genetic cause (2). The term Harlequin Ichthyosis derives from newborns facial expression and the triangular and diamond shaped pattern of hyperkeratosis. The newborn mouth is pulled wide open, mimicking a clown's smile (5). The underlying genetic abnormality in Harlequin Ichthyosis has been identified as a mutation in the lipid-transporter gene ABCA12 on chromosome 2. The presence of homozygous mutation in affected individuals supports an autosomal recessive pattern of inheritance (4). Immuno histo cytochemical examination of the skin reveals characteristic abnormalities in the structure of lamellar granules and in the expression of epidermal keratin (3).

CASE REPORT: Mrs. X, 23 years old, G2P1D1 at 27 weeks with previous neonatal death at 2 months after birth now diagnosed to have Ichthyosis by ultrasound scan. Patient conceived after ovulation induction, took her folic acid tablets. Dating scan was done at 12 weeks; blood sugars evaluated and were within normal limits. She had a $2^{\text {nd }}$ degree consanguineous marriage. Her $1^{\text {st }}$ baby died 2 months after birth, Autopsy examination and skin biopsy showed Ichthyosis.

Examination: Her general condition was fair, she was afebrile, weight - $72 \mathrm{kgs}$, height - $156.5 \mathrm{cms}$, no pallor, no icterus, no pedal edema. Blood pressure - 100/70 mm of Hg. Urine albumin absent. Chest, cardiovascular system, CNS examination was within normal limits. On per abdomen examination she had a 28 week size pregnancy with transverse presentation, liquor was clinically adequate, foetal heart rate (FHR) was 146/min regular, uterus was relaxed.

Investigation: Routine biochemistry and thyroid function test were within normal limits.

Dating scan - Single live intrauterine gestation corresponding to 12 weeks +6 days, placenta anterior, normal liquor, NT - 2.3mm, Nasal Bone seen, Ductus venosus normal flow. 


\section{CASE REPORT}

Anomaly scan - Single live intrauterine gestation corresponding to 22 weeks, placenta anterior, liquor normal, estimated foetal weight - 540 gms, upper limb - complete opening and closing of hands not seen, lower limb - abnormal toes seen in feet, foot measured $3.7 \mathrm{cms}$ ( mean $3.9 \mathrm{cms}$ ).

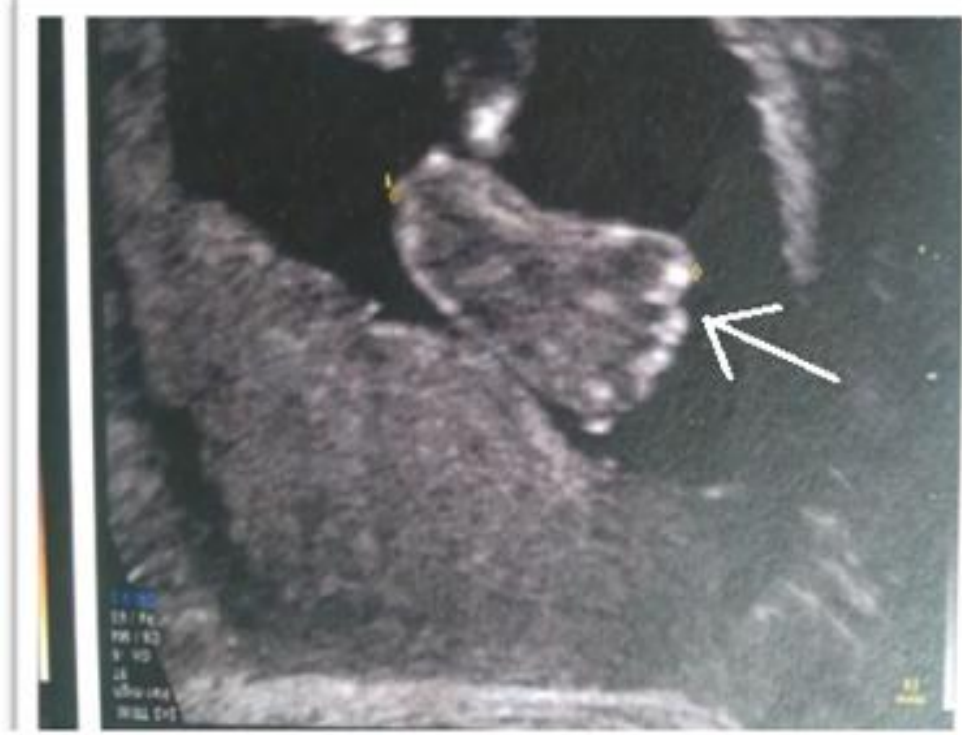

Abnormal curvature of toes

Foot measured $3.7 \mathrm{cms}(3.9 \mathrm{Cms}$ )

Repeat scan@ @26 weeks - Abnormal facial profile - Dysmorphic facies, abnormal curvature of toes, complete opening of hands not seen, fetal mouth persistently open, features suggestive of Ichthyosis.

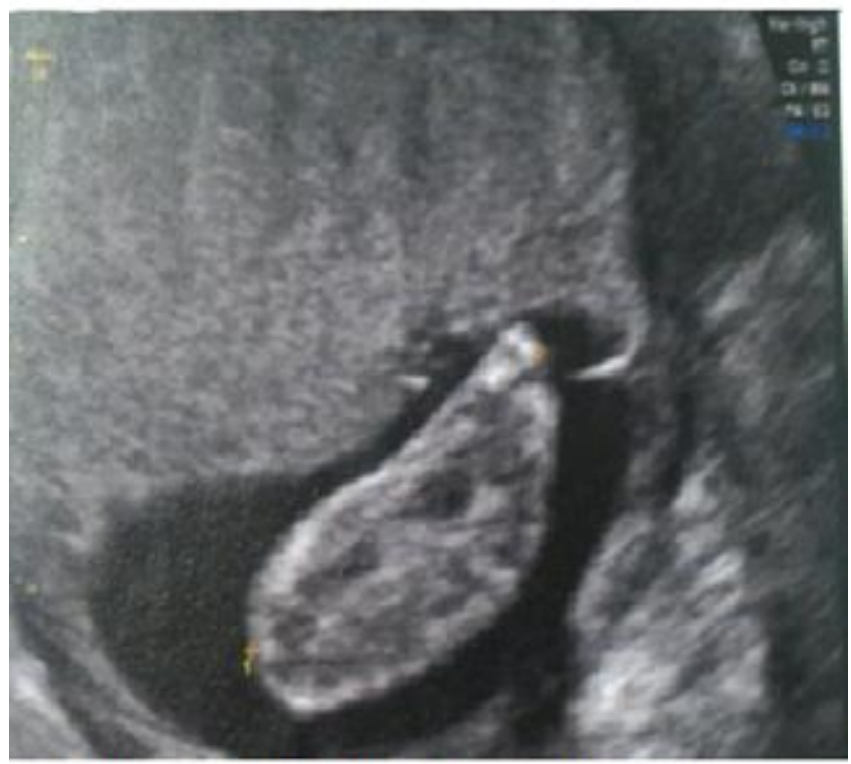

Abnormal curvature of foot@26

weeks 


\section{CASE REPORT}

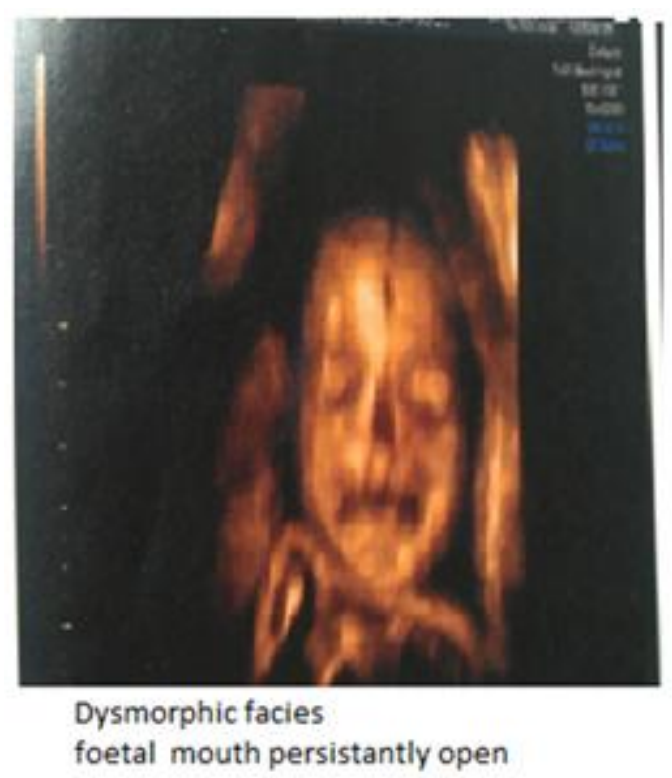

DISCUSSION: Mrs. X showed anomaly scan with features of incomplete opening and closing of hands, abnormal toes seen in feet, abnormal curvature of toes and foot measuring $3.7 \mathrm{cms}$ ( mean 3.9 $\mathrm{cms}$ ). In view of the previous history of Harlequin Ichthyosis and the present finding the possibility of evolving Ichthyosis was considered. Repeat scan was suggested after 4 weeks. In addition to the above features, the fetus showed dysmorphic facies and wide open mouth. Couple was informed about the fetal condition and the need for follow up monitoring. At 30 weeks of gestation, Mrs. X had preterm premature rupture of membrane and delivered a $1.3 \mathrm{~kg}$ boy baby. Baby cried immediately after birth, placenta weighed 390 gms. Physical assessment of the fetus at birth was done and revealed open mouth, dysmorphic facies, abnormal curvature of toes, incomplete opening and closing of hands, skin peeling.

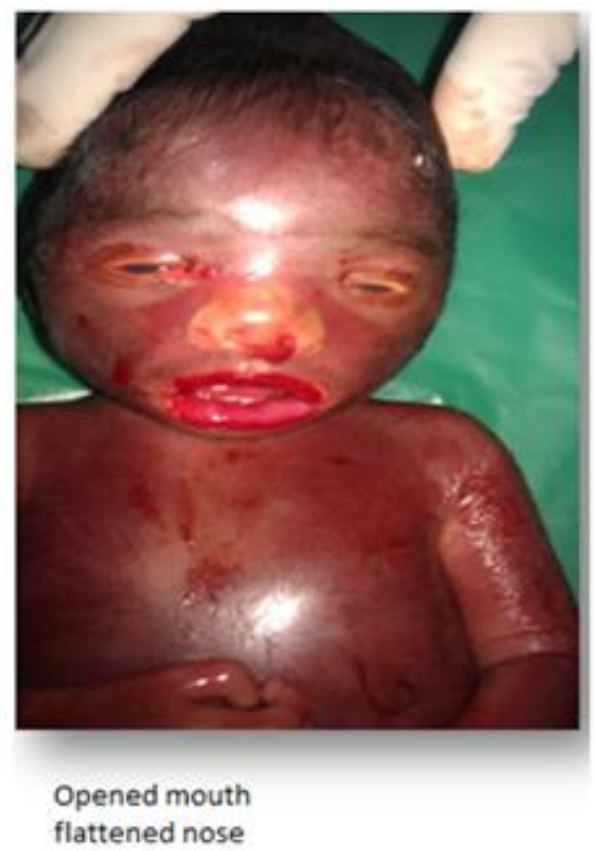




\section{CASE REPORT}

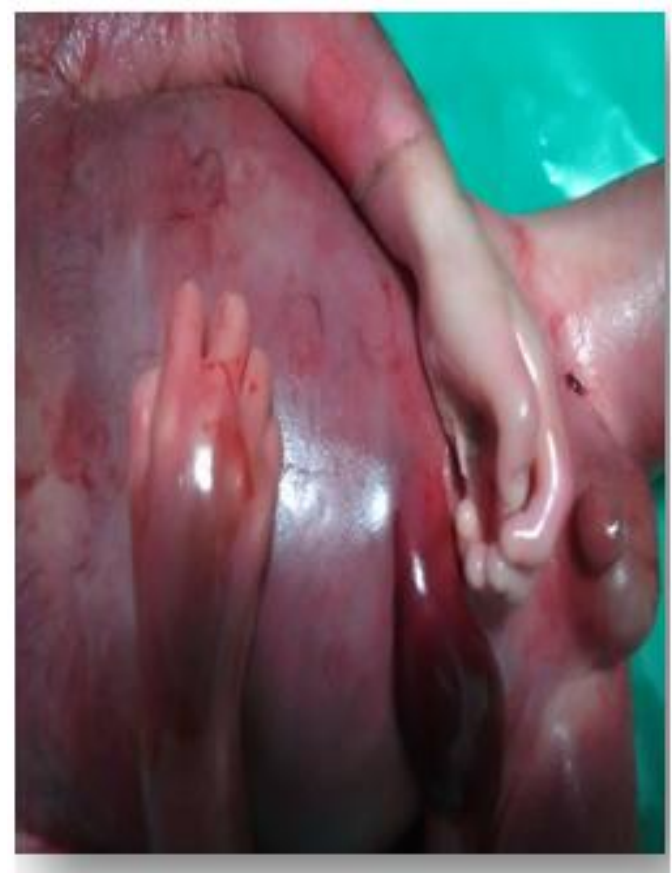

Incomplete opening and closing of hands

Skin peeling noted

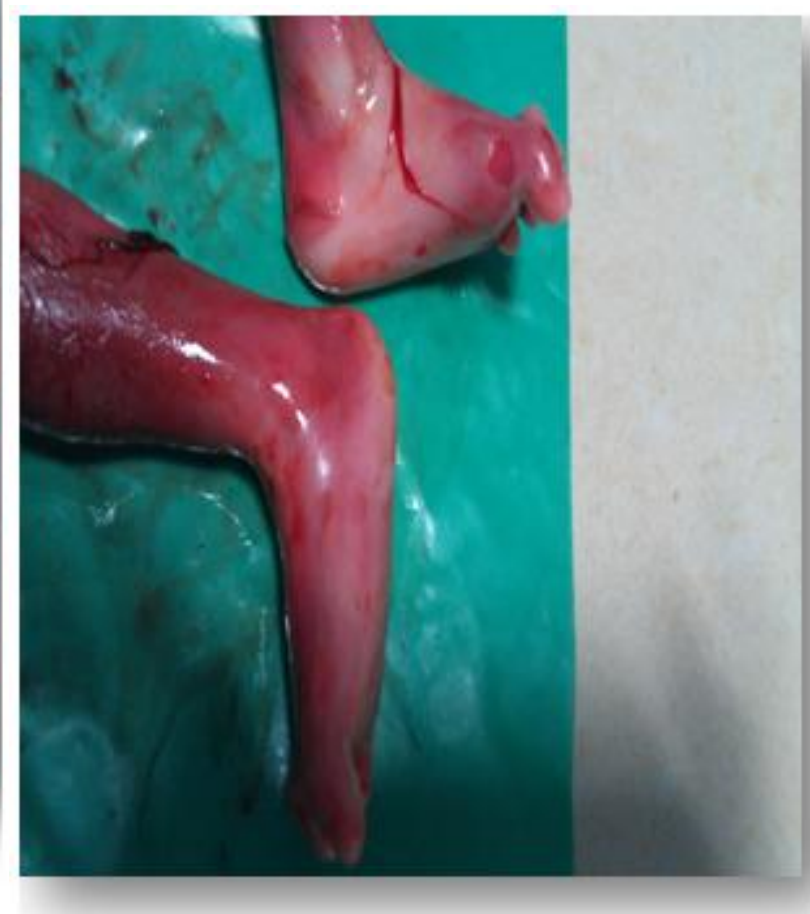

Abnormal curvature of toes

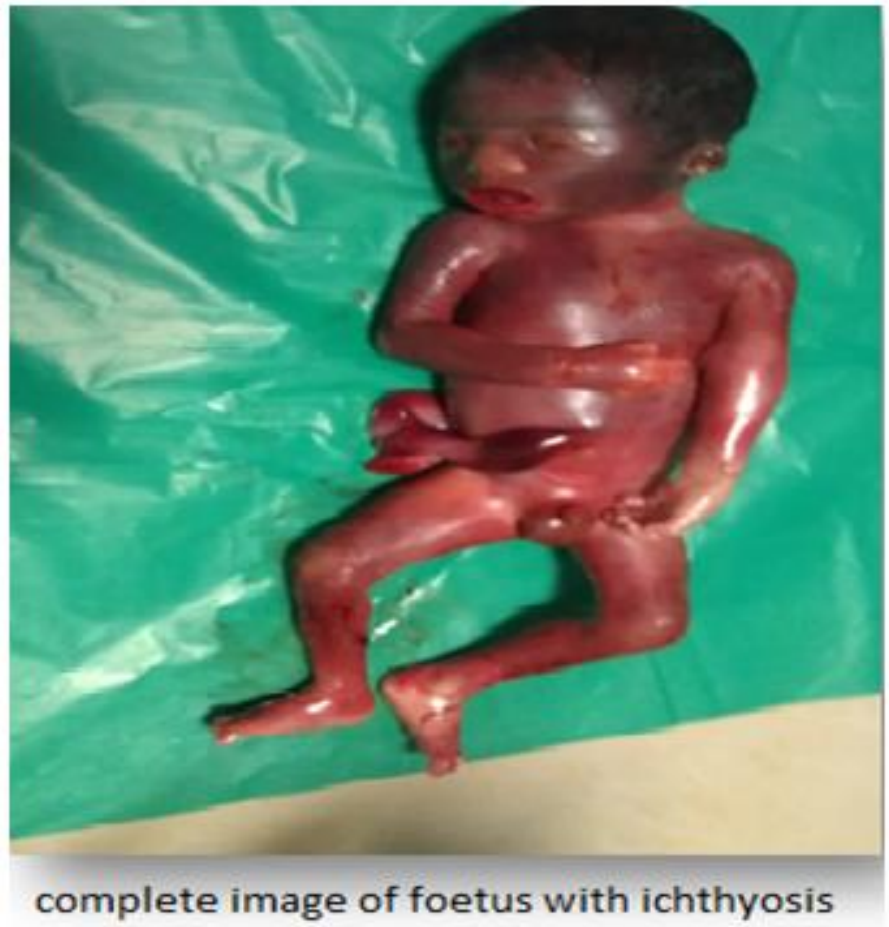


Baby died on day 1 of life due to dehydration and sepsis. Skin biopsy was taken to access the histologic characteristics of the cells. They revealed hyperkeratotic skin cells. Genetic testing was also done and revealed Harlequin Ichthyosis. Postnatal counselling was given to the couple. The chance of $25-50 \%$ recurrence (6) of this autosomal recessive condition was also explained.

\section{REFERENCES:}

1. Akiyama M, Mutations in lipid transporter ABCA12 in harlequin Ichthyosis and functional recovery by corrective gene transfer. J Clin Invest. 2005 Jul; 115 (7):1777-84.

2. Akiyama M. The pathogenesis of severe congenital Ichthyosis of the neonate. J Dermatol Sci. 1999 Sep; 21(2):96-104.

3. Gene Review: Autosomal Recessive Congenital Ichthyosis

4. Hovnanian A. Harlequin Ichthyosis unmasked: a defect of lipid transport. J Clin Invest. 2005 Jul;115 (7):1708-10.

5. Kelsell DP, O'Toole EA. Mutations in ABCA12 underlie the severe congenital skin disease harlequin Ichthyosis. Am J Hum Genet. 2005 May; 76(5):794-803. Epub 2005 Mar 8.

6. Moskowitz DG, Pathophysiologic basis for growth failure in children with Ichthyosis: an evaluation of cutaneous ultrastructure, epidermal permeability barrier function, and energy expenditure. J Pediatr. 2004 Jul; 145(1):82-92.

\section{AUTHORS:}

1. Shery Angel Rajakumar

2. Thirumal R.

3. A. P. Nalini

4. Anurag Vashista

5. Rontgen R.

\section{PARTICULARS OF CONTRIBUTORS:}

1. Assistant Professor, Department of Obstetrics \& Gynaecology, Chettinad Hospital and Research Institute.

2. Senior Resident, Department of Orthopaedics, Chettinad Hospital and Research Institute.

3. Professor, Department of Obstetrics \& Gynaecology, Chettinad Hospital and Research Institute.
4. Senior Resident, Department of Obstetrics \& Gynaecology, Chettinad Hospital and Research Institute.

5. Final Year Graduate, Department of Obstetrics \& Gynaecology, Sri Ramachandra University Chennai.

\section{NAME ADRRESS EMAIL ID OF THE CORRESPONDING AUTHOR:}

Dr. Shery Angel Rajakumar,

Chettinad Hospital and Research Institute,

Kelambakkam, Chennai,

Tamilnadu - 603103.

Email - sheryangel@gmail.com

Date of Submission: 20/07/2013.

Date of Peer Review: 22/07/2013.

Date of Acceptance: 07/08/2013.

Date of Publishing: 10/08/2013. 